\title{
Home produced eggs: An important pathway of human exposure to perfluorobutanoic acid (PFBA) and perfluorooctanoic acid (PFOA) around a fluorochemical industrial park in China
}

\author{
Hongqiao Su ${ }^{\text {a,b }}$, Yajuan Shi ${ }^{\text {a }}$, Yonglong Lu ${ }^{\text {a,* }}$, Pei Wang a , Meng Zhang ${ }^{\text {a,b }}$, Andrew Sweetman ${ }^{\text {c,d }}$, \\ Kevin Jones ${ }^{c}$, Andrew Johnson ${ }^{\mathrm{d}}$ \\ a State Key Laboratory of Urban and Regional Ecology, Research Center for Eco-Environmental Sciences, Chinese Academy of Sciences, Beijing 100085, China \\ b University of Chinese Academy of Sciences, Beijing 100049, China \\ ' Lancaster Environment Centre, Lancaster University, Lancaster LA1 4YQ UK \\ ' Centre for Ecology \&' Hydrology, Wallingford, OX 10 8BB, UK
}

\section{A R T I C L E I N F O}

\section{Article history:}

Received 1 November 2016

Received in revised form 19 January 2017

Accepted 21 January 2017

Available online 27 January 2017

\section{Keywords:}

PFOA

PFBA

Home produced eggs

Commercially produced eggs

Fluorochemical industrial park

Health risk

\begin{abstract}
A B S T R A C T
Dietary intake is considered to be a major pathway of human exposure to perfluoroalkyl acids (PFAAs). Chicken egg is an important contributor to the Chinese diet. In the present study, PFAAs in home produced eggs (HPEs) and commercially produced eggs (CPEs) surrounding a fluorochemical industrial park (FIP) in China were investigated. PFAAs in HPEs decreased with increasing distance from the FIP. HPEs were much more contaminated than CPEs, with PFAAs in CPEs comparable to or lower than those in HPEs from $20 \mathrm{~km}$ away from the FIP. PFOA concentrations in HPEs were higher than the levels of PFOA in eggs from other studies reported so far. For the first time, PFBA was reported in eggs and detected in all egg samples. PFOA and PFBA were the predominant forms in HPEs, while PFOA, PFBA and PFOS dominated in CPEs. For PFOA, estimated daily intakes (EDI) were $233 \mathrm{ng} / \mathrm{kg} \cdot \mathrm{bw} / \mathrm{day}$ for adults and $657 \mathrm{ng} / \mathrm{kg} \cdot \mathrm{bw} / \mathrm{day}$ for children who consume HPEs at households about $2 \mathrm{~km}$ away from the FIP. The EDI of PFOA for children via HPEs exceeded the reference dose value ( $333 \mathrm{ng} / \mathrm{kg} \cdot \mathrm{bw} / \mathrm{day}$ ) proposed by the Environmental Working Group.
\end{abstract}

(c) 2017 Elsevier Ltd. All rights reserved.

\section{Introduction}

Perfluoroalkyl acids (PFAAs) represent a family of synthetic organic compounds characterized by a fully fluorinated linear carbon chain with a hydrophilic head (Buck et al., 2011). Due to their hydrophobic and lipophobic nature, as well as their chemical and thermal stability, they have been widely used for over 60 years in a number of consumer and industrial applications (Ericson Jogsten et al., 2012). Among the PFAAs are perfluoroalkyl sulfonates (PFSAs) and perfluoroalkyl carboxylates (PFCAs), of which perfluorooctane sulfonate (PFOS) and perfluorooctanoic acid (PFOA) are most widely detected in the environment, wildlife and humans around the world (Giesy and Kannan, 2001; Wang et al., 2014). These chemicals have attracted significant attention from scientists and regulators because of their persistence, bioaccumulation and toxicity, as well as their ability to be transported at great distances (Lau et al., 2007; Fromme et al., 2009). For the purpose of globally restricting the uses and production, PFOS, its salts, and perfluorooctane sulfonyl fluoride (POSF) were listed as persistent organic pollutants

\footnotetext{
* Corresponding author.

E-mail address: yllu@rcees.ac.cn (Y. Lu).
}

(POPs) in Annex B of the Stockholm Convention in May 2009 (UNEP, 2009). Additionally, PFOA and its salt ammonium perfluorooctanoate (APFO) were added to the Candidate list of Substances of Very High Concern (SVHC) by the European Chemicals Agency (ECHA, 2013). As a result of these regulations, the manufacture of PFAAs has shifted toward less regulated countries including China to meet increasing demands and toward unregulated short-chain and new polyfluorinated PFAAs homologues.

Epidemiologic research suggests that PFOS and PFOA levels may be associated with reduced birth weight (Fei et al., 2007; Stein et al., 2009), increased blood cholesterol concentrations (Nelson et al., 2010), kidney and testicular cancer (Barry et al., 2013), and hyperuricemia (Steenland et al., 2010; Geiger et al., 2013). Diet, drinking water, air inhalation, and dust ingestion have been identified as main human exposure routes for PFAAs (Fromme et al., 2009; D'Hollander et al., 2010). The published investigations to date are mostly concerned with exposure of the general population (Haug et al., 2010; Domingo et al., 2012; Shan et al., 2016), while few studies reported on exposure pathways for residents near hot spot areas, such as manufacturing facilities. Some of these residents manage their own livestock or grow vegetables for basic subsistence and may inadvertently consume contaminated food (Brambilla et al., 2015). 
Chicken egg, an important contributor to the Chinese diet, constitutes a good protein and vitamin source and is of economic importance (Iddamalgoda et al., 2001). Nowadays, there is a general perception that free-range eggs are attributed a healthier nature and higher nutritional qualities (Waegeneers et al., 2009). Nevertheless, more and more studies revealed in home produced eggs (HPEs) a high contamination levels of POPs, such as PFAAs (Zafeiraki et al., 2016), dioxins and polychlorinated biphenyls (Van Overmeire et al., 2009; Hoogenboom et al., 2016; Polder et al., 2016), and halogenated flame retardants (Zheng et al., 2012).

Our previous studies have investigated the transportation of PFAAs from a fluorochemical industrial park (FIP) to the surrounding environment and elevated PFOA and C4-C7 PFCAs levels were found in indoor and outdoor dusts (Su et al., 2016), surface and ground waters (Liu et al., 2016), and sediments (Wang et al., 2016). In this study, we examined PFAAs in HPEs and commercially produced eggs (CPEs) from households surrounding the FIP. The main objectives of the study were: 1) to examine PFAAs in egg yolks, egg whites and whole eggs separately for distribution of PFAAs in different parts of the egg; 2 ) to investigate the levels and composition profiles of PFAAs in eggs; 3 ) to assess the human risks of PFAAs via consumption of these eggs to the local residents.

\section{Materials and methods}

\subsection{Sampling design and collection}

The selected FIP is located in Huantai county, Shandong province, in northern China. The FIP began to produce polytetrafluoroethylene (PTFE) in 2001, and the production has been expanded with an average annual growth rate of $25 \%$ since then (Wang et al., 2016). The capacity of PTFE production was expanded to over 49, 000 tons by the end of 2013. Huantai county is densely populated with a population of about 0.5 million in 2013, of which $81 \%$ live in rural areas. A total of 16 egg samples were collected from households around the FIP in October of 2015 (Fig. 1). Some of the local residents rear chickens domestically ( $\mathrm{n}=4$, site 1-4), while the others buy eggs from nearby supermarkets
( $\mathrm{n}=12$, site $5-16$ ). After sampling, the eggs were taken to laboratory and extracted within 1 week. Each sample consisted of 3 individual eggs.

\subsection{Chemicals and regents}

All samples were analyzed for 12 PFAAs, including 9 PFCAs with carbon lengths from C4 to C12 and 3 PFSAs (Table S1). All native and masslabeled PFAAs standards were purchased from Wellington Laboratories with purities of $>98 \%$ (Guelph, Canada). HPLC grade methyl tert-butyl ether (MTBE), methanol and acetonitrile (ACN) were purchased from J.T. Baker (Phillipsburg, USA). Tetrabutylammonium hydrogensulfate (TBAHS), sodium carbonate $\left(\mathrm{Na}_{2} \mathrm{CO}_{3}\right)$, anhydrous sodium sulfate, and ammonium acetate were purchased from Sigma-Aldrich Co. (St. Louis, USA). Milli-Q water was obtained from a Milli-Q Gradient A-10 (Millipore, Bedford, USA).

\subsection{Sample extraction and instrumental analysis}

The albumen of one egg was separated from the yolk and analyzed individually, while the other two eggs were homogenized together. The albumen, yolks and whole egg samples were all analyzed with the method below.

PFAAs were extracted using an ion pairing method described previously (Hansen et al., 2001) with some modifications. Approximately $1 \mathrm{~g}$ of the egg sample was spiked with $5 \mathrm{ng}$ mass-labeled internal standard and mixed with $1 \mathrm{~mL}$ of $0.5 \mathrm{M}$ TBAHS and $2 \mathrm{~mL}$ of $0.25 \mathrm{M}$ sodium carbonate buffer ( $\mathrm{pH} 10$ ). Subsequently, $5 \mathrm{~mL}$ of MTBE was added and shaken for $20 \mathrm{~min}$. After centrifuging for $20 \mathrm{~min}$ at $3500 \mathrm{r} / \mathrm{min}$, the supernatant MTBE was collected. The process of extraction was repeated twice. The supernatants were combined together, evaporated to neardryness under a gentle flow of high-purity nitrogen, and then reconstituted in $1 \mathrm{~mL}$ of methanol.

Clean-up was performed by solid phase extraction (SPE) using ENVICarb cartridges and Oasis-WAX cartridges. ENVI-Carb cartridges were used to remove the interferences in eggs (Ahrens et al., 2011; Eriksson et al., 2016; Zafeiraki et al., 2016). Supelco ENVI-Carb cartridges

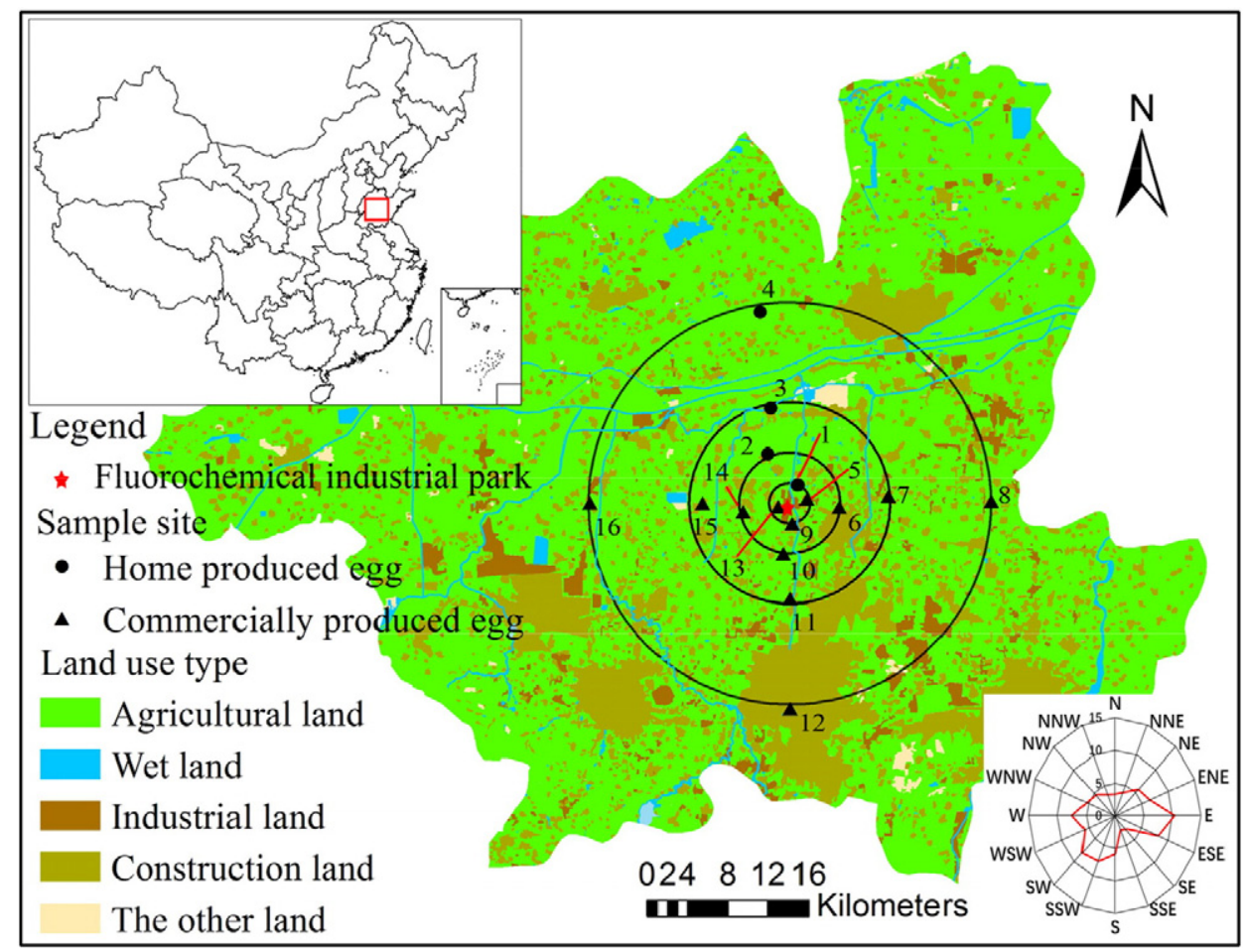

Fig. 1. Map of the study area and sampling sites. 
(250 mg, 3 mL, 142 Sigma-Aldrich, St. Louis, USA) were preconditioned with $1 \mathrm{~mL}$ methanol for three times and then the sample extracts were loaded and collected. The samples were further eluted by passing $1 \mathrm{~mL}$ of methanol through three times. All the extracts were diluted in $100 \mathrm{~mL}$ of Milli-Q water and subjected to Oasis WAX cartridges for further SPE cleanup. The Oasis WAX cartridges ( $6 \mathrm{cc}, 150 \mathrm{mg}, 30 \mu \mathrm{m}$, Waters, Milford, MA) were conditioned by passing through $4 \mathrm{~mL}$ of $0.1 \%$ ammonium hydroxide in methanol, followed by $4 \mathrm{~mL}$ of methanol and $4 \mathrm{~mL}$ of Milli-Q water successively. $100 \mathrm{~mL}$ of the samples were passed through the preconditioned cartridges. The cartridges were washed with $4 \mathrm{~mL}$ of $25 \mathrm{mM}$ ammonium acetate ( $\mathrm{pH} 4$ ) and air-dried. The target analytes were then eluted with $4 \mathrm{~mL}$ of methanol, followed by $4 \mathrm{~mL}$ of $0.1 \%$ ammonium hydroxide in methanol. The final elution was concentrated to $1 \mathrm{~mL}$ under a gentle stream of high-purity nitrogen, filtered through a $0.2 \mu \mathrm{m}$ nylon filter into a $1.5 \mathrm{~mL}$ auto-sampler vial fitted with polypropylene cap for HPLC analysis.

All PFAAs were analyzed via an Agilent 1290 Infinity HPLC System coupled to an Agilent 6460 Triple Quadrupole LC/MS System (Agilent Technologies, Palo Alto, CA). The instrument conditions are listed in Tables S1, S2.

\subsection{Quality control and quality assurance}

To avoid contamination, no PTFE or other fluoropolymer materials were used during sample preparation. Procedural blanks and solvent blanks were included with each batch of 10 samples. Matrix spike recovery was performed with $5 \mathrm{ng}$ native PFAAs standards added into the egg whites, egg yolks and whole egg samples from the reference site, respectively. A 10-point standard calibration curve, from $0.01 \mathrm{ng} / \mathrm{mL}$ to $500 \mathrm{ng} / \mathrm{mL}$, was prepared for the quantification of individual PFAAs. The correlation coefficients $\left(\mathrm{r}^{2}\right)$ were higher than 0.99 for all calibration curves. The Limit of Detection (LOD) and the Limit of Quantification (LOQ) were defined as the concentration that gave a signal to noise ratio of 3 and 10, respectively. Concentrations of all target PFAAs in any procedural and solvent blank were less than the LOD. Matrix spike recoveries of target compounds ranged from $68 \pm 1 \%$ to $134 \pm 7 \%$. Detailed QA/QC measurements of PFAAs in egg samples are shown in Table S3.

\section{Results and discussion}

\subsection{Occurrence of PFAAs in egg yolks}

Concentrations of 12 PFAAs calculated on a wet weight (ww) basis detected in chicken egg yolks, egg whites and whole egg samples are presented in Table 1, Table 2 and Table S4. PFBS and PFHxS were not detected in any samples, and so will not be discussed any further.

In yolks of HPEs ( site 1-4), detection frequency of C4 PFCA, C8-C12 PFCAs and PFOS was $100 \%$, and those of C5, C6 and C7 PFCAs were $75 \%$, $50 \%$ and $25 \%$, respectively. The concentrations of $\Sigma$ PFAAs (sum of 10 PFAAs except for PFBS and PFHxS) were 482, 162, 63.7 and $8.99 \mathrm{ng} / \mathrm{g}$ for site 1, 2, 3 and 4, respectively, which suggested a decrease with increasing distance from the FIP. Concentrations of C9-C12 PFCAs and PFOS were similar for samples taken from these four sites. PFOA (5.11-368 ng/g) was the most abundant congener and contributed $69 \%$ of $\Sigma$ PFAAs (Fig. 2). PFBA (1.75-110 ng/g) was the second most abundant congener in these samples with an average contribution of $22 \%$ of $\Sigma$ PFAAs. PFOS $(0.73-1.39 \mathrm{ng} / \mathrm{g})$ contributed $3.6 \%$ of the total and the remaining seven PFCAs accounted for $5 \%$. Both PFOA and PFBA concentrations declined with increasing distance from the FIP, which is consistent with environmental media such as surface water and dust in this area (Liu et al., 2016; Su et al., 2016). In the environmental media around the FIP, PFOA and C4-C7 PFCAs were dominated (Liu et al., 2016; Su et al., 2016). Unlike the environmental media, in which the concentrations and contributions to IPFAAs of PFPeA, PFHxA and PFHpA were similar to PFBA, the egg yolks contained much lower proportions of these three homologues than that of PFBA. This could be because PFBA concentrations are higher than these three homologues in the diet of the chickens, for example in maize from the farmland around the FIP (Krippner et al., 2014).

In yolks of CPEs ( site 5-16), the detection frequency of PFBA, PFOA and PFOS was $100 \%$, whereas other PFAAs were less frequently detected. PFHpA was not detected in any sample. ¿PFAAs concentrations ranged from 0.77 to $9.14 \mathrm{ng} / \mathrm{g}$, which were similar to that of HPE yolk sample from site 4, $20 \mathrm{~km}$ away from the FIP. Living environment and eating habits of the hens may explain the difference between PFAAs levels in HPEs and CPEs (Brambilla et al., 2015; Zafeiraki et al., 2016). For example, laying hens in commercial farms usually eat processed or packaged food, while free foraging hens consume soil, earthworms, insects, weeds, food leftovers and local water. In the yolks of CPEs, contributions of PFBA (27-62\%, with a mean 39\%), PFOA (6-51\%, 38\%) and PFOS (9$56 \%, 30 \%$ ) to $\Sigma$ PFAAs were comparable with each other (Fig. 2). The contribution of the remaining PFCAs to $\Sigma$ PFAAs was about $3 \%$. PFOA concentrations ranged from 0.09 to $2.66 \mathrm{ng} / \mathrm{g}$, which were lower than that of HPE yolk sample from site 4 . The concentrations of PFBA (0.31$5.64 \mathrm{ng} / \mathrm{g}$ ) were similar to that of the HPE yolk sample from site 4, while much lower than that of samples from sites $1-3$. There was not much difference in PFOS concentrations between commercially produced and HPE yolks.

Compared with previous studies (Table S5), PFAAs levels in HPE from site 4 or in CPEs were similar with that in HPEs from Netherlands

Table 1

PFAAs concentrations ( $\mathrm{ng} / \mathrm{g}$ ) in home produced eggs (HPEs, $\mathrm{n}=4$ ).

\begin{tabular}{|c|c|c|c|c|c|c|c|c|c|c|c|c|c|c|}
\hline Site & $\begin{array}{l}\text { Distance } \\
(\mathrm{km})\end{array}$ & PFBA & PFPeA & PFHxA & PFHpA & PFOA & PFNA & PFDA & PFUdA & PFDoA & PFBS & PFHxS & PFOS & ¿PFAAs \\
\hline \multicolumn{15}{|c|}{ Egg yolks } \\
\hline 1 & 2 & 110 & 0.57 & 0.20 & 0.29 & 368 & 0.87 & 0.73 & 0.13 & 0.20 & $<0.02$ & $<0.02$ & 1.39 & 482 \\
\hline 2 & 5 & 16.0 & 0.11 & $<0.02$ & $<0.03$ & 140 & 0.97 & 1.83 & 1.26 & 0.78 & $<0.02$ & $<0.02$ & 1.37 & 162 \\
\hline 3 & 10 & 23.8 & 0.17 & 0.08 & $<0.03$ & 36.4 & 0.94 & 0.93 & 0.50 & 0.22 & $<0.02$ & $<0.02$ & 0.73 & 63.7 \\
\hline 4 & 20 & 1.75 & $<0.05$ & $<0.02$ & $<0.03$ & 5.11 & 0.30 & 0.39 & 0.15 & 0.17 & $<0.02$ & $<0.02$ & 1.11 & 8.99 \\
\hline \multicolumn{15}{|c|}{ Egg whites } \\
\hline 1 & 2 & 6.97 & $<0.05$ & 0.02 & $<0.03$ & 1.46 & 0.01 & $<0.02$ & $<0.04$ & 0.08 & $<0.02$ & $<0.02$ & $<0.02$ & 8.54 \\
\hline 2 & 5 & 1.15 & $<0.05$ & $<0.02$ & $<0.03$ & 0.32 & $<0.01$ & $<0.02$ & $<0.04$ & $<0.02$ & $<0.02$ & $<0.02$ & $<0.02$ & 1.47 \\
\hline 3 & 10 & 2.43 & $<0.05$ & $<0.02$ & $<0.03$ & 0.29 & $<0.01$ & $<0.02$ & $<0.04$ & 0.05 & $<0.02$ & $<0.02$ & $<0.02$ & 2.76 \\
\hline 4 & 20 & 0.24 & $<0.05$ & 0.02 & $<0.03$ & 0.05 & $<0.01$ & $<0.02$ & $<0.04$ & 0.03 & $<0.02$ & $<0.02$ & $<0.02$ & 0.35 \\
\hline \multicolumn{15}{|c|}{ Whole eggs } \\
\hline 1 & 2 & 22.5 & 0.22 & 0.04 & $<0.03$ & 125 & 0.19 & 0.26 & 0.08 & 0.10 & $<0.02$ & $<0.02$ & 0.86 & 149 \\
\hline 2 & 5 & 5.40 & $<0.05$ & $<0.02$ & $<0.03$ & 41.5 & 0.15 & 0.40 & 0.13 & $<0.02$ & $<0.02$ & $<0.02$ & 0.45 & 48.1 \\
\hline 3 & 10 & 12.0 & 0.07 & $<0.02$ & $<0.03$ & 18.0 & 0.33 & 0.48 & 0.12 & 0.12 & $<0.02$ & $<0.02$ & 0.71 & 31.9 \\
\hline 4 & 20 & 0.54 & $<0.05$ & $<0.02$ & $<0.03$ & 2.54 & 0.14 & 0.17 & $<0.04$ & 0.05 & $<0.02$ & $<0.02$ & 0.32 & 3.75 \\
\hline
\end{tabular}


Table 2

PFAAs concentrations ( $\mathrm{ng} / \mathrm{g}$ ) in Commercially produced eggs (CPEs, $\mathrm{n}=12$ ).

\begin{tabular}{|c|c|c|c|c|c|c|c|c|c|c|c|c|c|}
\hline & PFBA & PFPeA & PFHxA & PFHpA & PFOA & PFNA & PFDA & PFUdA & PFDoA & PFBS & PFHxS & PFOS & ¿PFAAs \\
\hline \multicolumn{14}{|l|}{ Egg yolks } \\
\hline MIN & 0.31 & $<0.05$ & $<0.02$ & $<0.03$ & 0.09 & $<0.01$ & $<0.02$ & $<0.04$ & $<0.02$ & $<0.02$ & $<0.02$ & 0.31 & 0.77 \\
\hline MAX & 5.64 & 0.05 & 0.07 & $<0.03$ & 2.66 & 0.08 & 0.04 & 0.07 & 0.09 & $<0.02$ & $<0.02$ & 1.68 & 9.14 \\
\hline Mean* & 1.72 & 0.05 & 0.04 & $<0.03$ & 1.20 & 0.03 & 0.03 & 0.06 & 0.04 & $<0.02$ & $<0.02$ & 0.85 & 3.85 \\
\hline Median & 1.02 & $<0.05$ & $<0.02$ & $<0.03$ & 0.78 & $<0.01$ & $<0.02$ & $<0.04$ & 0.04 & $<0.02$ & $<0.02$ & 0.78 & 3.15 \\
\hline $\mathrm{n}>\mathrm{LOD}(\%)$ & $12(100)$ & $1(8)$ & $3(25)$ & $0(0)$ & $12(100)$ & $5(42)$ & $4(33)$ & $2(17)$ & $9(75)$ & $0(0)$ & $0(0)$ & $12(100)$ & \\
\hline \multicolumn{14}{|l|}{ Egg whites } \\
\hline MIN & 0.16 & $<0.05$ & $<0.02$ & $<0.03$ & $<0.01$ & $<0.01$ & $<0.02$ & $<0.04$ & $<0.02$ & $<0.02$ & $<0.02$ & $<0.02$ & 0.19 \\
\hline MAX & 0.52 & $<0.05$ & 0.03 & $<0.03$ & 0.12 & 0.06 & 0.05 & 0.04 & 0.04 & $<0.02$ & $<0.02$ & $<0.02$ & 0.59 \\
\hline Mean* & 0.33 & $<0.05$ & 0.03 & $<0.03$ & 0.06 & 0.06 & 0.04 & 0.04 & 0.03 & $<0.02$ & $<0.02$ & $<0.02$ & 0.41 \\
\hline Median & 0.31 & $<0.05$ & $<0.02$ & $<0.03$ & 0.06 & $<0.01$ & $<0.02$ & $<0.04$ & $<0.02$ & $<0.02$ & $<0.02$ & $<0.02$ & 0.37 \\
\hline $\mathrm{n}>\mathrm{LOD}(\%)$ & $12(100)$ & $0(0)$ & $1(8)$ & $0(0)$ & $10(83)$ & $1(8)$ & $2(17)$ & $2(17)$ & $2(17)$ & $0(0)$ & $0(0)$ & $0(0)$ & \\
\hline \multicolumn{14}{|l|}{ Whole eggs } \\
\hline MIN & 0.25 & $<0.05$ & $<0.02$ & $<0.03$ & 0.04 & $<0.01$ & $<0.02$ & $<0.04$ & $<0.02$ & $<0.02$ & $<0.02$ & 0.35 & 0.83 \\
\hline MAX & 3.82 & $<0.05$ & 0.05 & $<0.03$ & 1.34 & 0.02 & $<0.02$ & $<0.04$ & $<0.02$ & $<0.02$ & $<0.02$ & 0.91 & 5.16 \\
\hline Mean* & 0.85 & $<0.05$ & 0.03 & $<0.03$ & 0.59 & 0.02 & $<0.02$ & $<0.04$ & $<0.02$ & $<0.02$ & $<0.02$ & 0.55 & 2.01 \\
\hline Median & 0.49 & $<0.05$ & 0.04 & $<0.03$ & 0.49 & $<0.01$ & $<0.02$ & $<0.04$ & $<0.02$ & $<0.02$ & $<0.02$ & 0.51 & 1.78 \\
\hline $\mathrm{n}>$ LOD $(\%)$ & $12(100)$ & $0(0)$ & $6(50)$ & $0(0)$ & $12(100)$ & $1(8)$ & $0(0)$ & $0(0)$ & $0(0)$ & $0(0)$ & $0(0)$ & $12(100)$ & \\
\hline
\end{tabular}

* Mean value is calculated based only on the concentrations above LOQ.

and Greece (Zafeiraki et al., 2016) or in CPEs from Sweden (Johansson et al., 2014; Gebbink et al., 2015), Norway (Haug et al., 2010) and China (Zhang et al., 2010). PFAAs in CPEs from several countries were below the LOQ, such as from the U.S.A (Schecter et al., 2010), U.K (Clarke et al., 2010), and Italy (Guerranti et al., 2013). Different PFAAs congener patterns were found among regions. PFOS was the major component in eggs from European countries, while PFOA was found to be the most prevalent PFAAs in eggs from China.

\subsection{Occurrence of PFAAs in egg whites, whole eggs and distribution pattern of PFAAs in eggs}

In all 16 egg whites, PFBA and PFOA were detected in 16 and 14 samples, respectively. The remaining PFCAs and PFOS were detected at low frequency or were not detected. Unlike PFAAs congener pattern in egg yolks, PFBA was the predominant form in egg whites, contributing $77 \%$ of $\Sigma$ PFAAs, followed by PFOA (17\%) (Fig. 2). Concentrations of PFBA (0.24-6.97 ng/g) and PFOA (0.05-1.46 ng/g) in whites of HPEs declined with increasing distance from the FIP. PFBA and PFOA concentrations in whites of CPEs, in the range of 0.16 to $0.52 \mathrm{ng} / \mathrm{g}$ and $<0.01$ to $0.12 \mathrm{ng} / \mathrm{g}$, resemble those in home produced samples from site 4 , the most distant location.

Distribution patterns of the three mostly detected PFAAs in egg yolk and egg white parts was examined (Fig. S1). In agreement with previous studies (Wang et al., 2008; Zafeiraki et al., 2016), approximately $100 \%$ of PFOS and $>90 \%$ of PFOA were found in the egg yolks. PFBA was firstly examined in eggs, and showed a little difference from the other PFAAs. Averagely $20 \%$ of PFBA (with a range from $6 \%$ to $48 \%$ ) was found in egg whites, although most of it was still distributed in egg yolks. This distribution pattern might be attributed to the different affinity between individual PFAA and the proteins in egg yolk and egg white parts.

In all whole egg samples, PFAAs concentrations were 2-8 times lower than that in corresponding egg yolk samples, while the congener patterns were similar (Fig. 2). Egg samples were prepared in different ways for analysis of PFAAs in previous studies. Some mixed the whole eggs (Clarke et al., 2010; Zhang et al., 2010; D'Hollander et al., 2011), while others homogenized the yolks only because the PFAAs they analyzed predominantly partition into the yolks (Johansson et al., 2014; Zafeiraki et al., 2016). Results of this study and a former study (Wang et al., 2008) showed that PFAAs concentrations in mixed whole eggs were diluted in comparison to that in egg yolks. Analysis of PFAAs in yolks solely would underestimate the health risk on account of the relatively higher proportion of PFBA in egg white. There are some groups who consume the egg whites in quantity while they control the egg yolks intake. These people include athletes (Deepak, 2016), patients at risk of vascular disease (Spence et al., 2010) and diabetics (Radzevičienè and Ostrauskas, 2012). As a result, only analysis of yolks was recommended when studying the PFSAs in eggs, while yolks and albumen should be analyzed separately when examining the PFCAs.

\subsection{Human exposure to PFAAs via egg consumption}

The uptake of PFAAs from HPEs was identified as an important exposure pathway for the residents near a manufacturing facility (Wang et al., 2010; D'Hollander et al., 2011). According to Shandong Statistic Year Book, the average egg consumption in the studied area was 37.5 g/day/person (SDSB, 2015). Applying an average body weight (bw) of $59.4 \mathrm{~kg}$ for adults and $21.1 \mathrm{~kg}$ for children (Zhang et al., 2010), daily intakes of several main PFAAs and $\Sigma$ PFAAs via HPEs and CPEs consumption were estimated (Table 3). Estimated Daily Intake (EDI) of PFAAs were calculated by EDI $(\mathrm{ng} / \mathrm{kg} \cdot \mathrm{bw} / \mathrm{day})=$ egg consumption $(\mathrm{g} /$ day) $\times$ PFAAs' concentration $(\mathrm{ng} / \mathrm{g}) /$ body weight $(\mathrm{kg})$. PFAAs' concentration referred to the sum of PFAAs in egg yolks and that in egg whites. As for EDI calculation of CPEs, arithmetic mean concentrations of PFAAs were used.

The reference dose (RfD) values proposed by the Environmental Working Group (EWG) are 25 and $333 \mathrm{ng} / \mathrm{kg}$ ·bw/day for PFOS and PFOA, respectively (Thayer and Houlihan, 2002) (Table S6). The EDIs of PFOS through all HPEs (0.46-3.01 ng/ $\mathrm{kg} \cdot \mathrm{bw} /$ day) and CPEs (0.54$1.52 \mathrm{ng} / \mathrm{kg} \cdot \mathrm{bw} /$ day) were comparable, accounting for $1.8-12.0 \%$ of the RfD. It is alarming that the EDI of PFOA via HPEs from site 1 was 233 and $657 \mathrm{ng} / \mathrm{kg} \cdot \mathrm{bw} /$ day for adults and children, which were close to the RfD for adults and about 2 times the RfD for children. Due to low concentrations of PFAAs found in eggs, reports on EDI via eggs are scarce. The highest EDI of PFOA in the present study were at least 2 orders of magnitude higher than the average values estimated in HPEs from Netherlands and Greece $(0.34-2.7 \mathrm{ng} / \mathrm{kg} \cdot \mathrm{bw} /$ day) (Zafeiraki et al., 2016) and CPEs from Sweden ( $0.012 \mathrm{ng} / \mathrm{kg} \cdot \mathrm{bw} / \mathrm{day})$ (Gebbink et al., 2015). A recent study reported total dietary intake of PFOA was $11.95 \mathrm{ng} / \mathrm{kg} \cdot \mathrm{bw} /$ day for general population in China (Shan et al., 2016), being 20 times lower than the EDI via HPEs from site 1. Elevated PFAAs' EDI values via consumption of HPEs were also found in nearby communities of a fluorochemical plant in Wuhan, China (Wang et al., 2010) and in Zwijndrecht, Belgium (D'Hollander et al., 2011). The EDIs of PFOA in their study were not determined due to low concentrations of PFOA in eggs. However, the EDIs of PFOS were 1.0-1.6 times the reference dose (25 ng/ $\mathrm{kg} \cdot \mathrm{bw} / \mathrm{day})$ and up to $496 \mathrm{ng} / \mathrm{kg} \cdot \mathrm{bw} /$ day in the location of China and Belgium, respectively. These values were much 


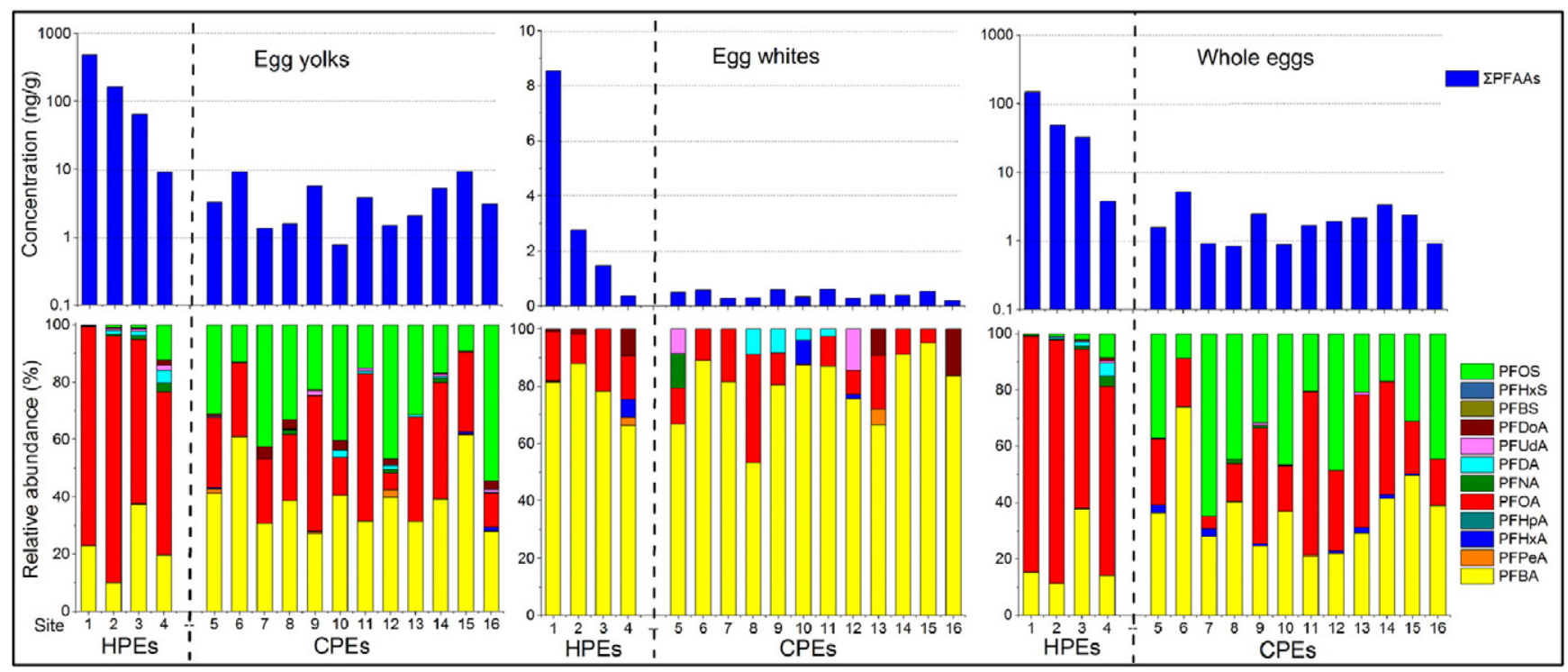

Fig. 2. PFAAs in egg yolks, egg whites and whole eggs of home produced eggs (HPEs) and commercially produced eggs (CPEs).

higher than that in the present study. This difference could most likely be attributed to different production pattern among the plants.

The EDI of PFBA via egg consumption ranged from 1.26 to $73.6 \mathrm{ng} /$ $\mathrm{kg} \cdot \mathrm{bw} /$ day for adults and 3.54 to $207 \mathrm{ng} / \mathrm{kg} \cdot \mathrm{bw} /$ day for children, respectively. There are few studies on human exposure and toxicology effect of PFBA, which might be due to shorter serum elimination half-lives of PFBA, 3 to 4 days (Chang et al., 2008). However, a recent study on PFAAs in autopsy tissues from the general population in Catalonia, Spain revealed high levels of short-chain PFAAs, especially PFBA (median values: 807 and 263 ng/g in lung and kidney, respectively) (Pérez et al., 2013). This implies that PFBA may accumulate in these human tissues rather than be excreted from the body. As an important short-chain alternative, PFBA has been detected across the globe in environmental samples (Wang et al., 2015; Lorenzo et al., 2016). Thus, human exposure pathways of PFBA is worthy of attention and health effects of PFBA exposure to local residents around the FIP via egg consumptions need urgent further investigation.

\section{Conclusion and perspective}

The present study investigated PFAAs in home and commercially produced eggs surrounding a fluorochemical industrial park in China. Egg yolks, egg whites and whole eggs were analyzed separately. Eggs were much more contaminated with PFAAs in HPEs than in CPEs, with the levels of PFAAs in CPEs comparable to or lower than that in HPE from site 4, $20 \mathrm{~km}$ away from the FIP. About $100 \%$ of the $\mathrm{C} 4-\mathrm{C} 12$ PFCAs and PFOS were detected in HPEs, while only PFBA, PFOA and

Table 3

Estimated Daily Intake (EDI) (ng/kg · bw/day) of PFAA via home produced eggs (HPEs) and commercially produced eggs (CPEs) consumption.

\begin{tabular}{|c|c|c|c|c|c|c|}
\hline & Site & Distance (km) & PFBA & PFOA & PFOS & ¿PFAAs \\
\hline \multicolumn{7}{|c|}{ HPEs $(n=4)$} \\
\hline \multirow[t]{4}{*}{ Adults } & 1 & 2 & 73.6 & 233 & 1.07 & 310 \\
\hline & 2 & 5 & 10.8 & 88.4 & 0.86 & 103 \\
\hline & 3 & 10 & 16.5 & 23.1 & 0.46 & 41.9 \\
\hline & 4 & 20 & 1.26 & 3.26 & 0.70 & 5.92 \\
\hline \multirow[t]{4}{*}{ Child } & 1 & 2 & 207 & 657 & 3.01 & 873 \\
\hline & 2 & 5 & 30.4 & 249 & 2.43 & 291 \\
\hline & 3 & 10 & 46.5 & 65.1 & 1.30 & 118 \\
\hline & 4 & 20 & 3.54 & 9.19 & 1.97 & 16.7 \\
\hline \multicolumn{7}{|c|}{$\operatorname{CPEs}(\mathrm{n}=12)$} \\
\hline Adults & Mean & & 1.30 & 0.79 & 0.54 & 2.69 \\
\hline Child & Mean & & 3.66 & 2.23 & 1.52 & 7.58 \\
\hline
\end{tabular}

PFOS were detected 100\% in CPEs. Concentrations of PFOA (5.11$368 \mathrm{ng} / \mathrm{g})$ and PFBA (1.75-110 ng/g) in HPEs decreased with increasing distance from the FIP. Concentrations of PFOA in HPEs except from site 4 were higher than those reported in previous studies across the world. To the best of our knowledge, this is the first study that measured PFBA in eggs and showed high concentrations and high detection frequency, although our observations were made from a relatively low number of HPE samples. Most of PFAAs distributed in egg yolks, while an average of $20 \%$ of PFBA found in egg white requires particular attention. Health risks of PFAAs via consumption of HPEs are of great concern for the local residents near the FIP. The EDIs of PFOA via HPE from site 1 were up to 233 and $657 \mathrm{ng} / \mathrm{kg} \cdot \mathrm{bw} /$ day for adults and children, which were close to and about 2 times the RfD value ( $333 \mathrm{ng} / \mathrm{kg}$ · bw/day) proposed by the Environmental Working Group, respectively. Therefore, CPEs are more recommended to consume for residents around the FIP.

It is important to note that our observations were made from a relatively low number of HPE samples, as a small number of local residents breed chicken themselves. More studies are required on health effects of PFAAs in home produced chicken eggs from hot spot areas in the future. In addition, PFOA could induce developmental cardiotoxicity in chicken embryos and hatchlings (Jiang et al., 2012), but little is known about the effects of PFOA on domestic animal production. This needs further study as well.

\section{Acknowledgements}

This study was supported by the International Scientific Cooperation Program [grant no. 2012DFA91150], the National Natural Science Foundation of China [grant no. 414201040045 and no. 41371488], and the Key Project of the Chinese Academy of Sciences [grant no. KZZD-EWTZ-12]. The UK authors are grateful for support from the NERC Newton Fund to assist their collaboration with China.

\section{Appendix A. Supplementary data}

Supplementary data to this article can be found online at http://dx. doi.org/10.1016/j.envint.2017.01.016.

\section{References}

Ahrens, L., Herzke, D., Huber, S., Bustnes, J.O., Bangjord, G., Ebinghaus, R., 2011. Temporal trends and pattern of polyfluoroalkyl compounds in Tawny Owl (Strix aluco) eggs from Norway, 1986-2009. Environ. Sci. Technol. 45, 8090-8097. 
Barry, V., Winquist, A., Steenland, K., 2013. Perfluorooctanoic acid (PFOA) exposures and incident cancers among adults living near a chemical plant. Environ. Health Perspect. $121,1313-1318$.

Brambilla, G., D'Hollander, W., Oliaei, F., Stahl, T., Weber, R., 2015. Pathways and factors for food safety and food security at PFOS contaminated sites within a problem based learning approach. Chemosphere 129, 192-202.

Buck, R.C., Franklin, J., Berger, U., Conder, J.M., Cousins, I.T., de Voogt, P., Jensen, A.A., Kannan, K., Mabury, S.A., van Leeuwen, S.P., 2011. Perfluoroalkyl and polyfluoroalkyl substances in the environment: terminology, classification, and origins. Integr. Environ. Assess. Manag. 7, 513-541.

Chang, S.C., Das, K., Ehresman, D.J., Ellefson, M.E., Gorman, G.S., Hart, J.A., Noker, P.E., Tan, Y.M., Lieder, P.H., Lau, C., Olsen, G.W., Butenhoff, J.L., 2008. Comparative pharmacokinetics of perfluorobutyrate in rats, mice, monkeys, and humans and relevance to human exposure via drinking water. Toxicol. Sci. 104, 40-53.

Clarke, D.B., Bailey, V.A., Routledge, A., Lloyd, A.S., Hird, S., Mortimer, D.N., Gem, M., 2010. Dietary intake estimate for perfluorooctanesulphonic acid (PFOS) and other perfluorocompounds (PFCs) in UK retail foods following determination using standard addition LC-MS/MS. Food Addit. Contam. 27, 530-545.

Deepak, S.H., 2016. Supplementing with Egg White Protein. http://www.healthguidance. org/entry/17025/1/Supplementing-With-Egg-White-Protein.html (accessed in 2016/ $12 / 21)$.

D'Hollander, W., de Voogt, P., Bervoets, L., 2011. Accumulation of perfluorinated chemicals in Belgian home-produced chicken eggs. Organohalogen Compd. 73, 917-920.

D'Hollander, W., de Voogt, P., De Coen, W., Bervoets, L., 2010. Perfluorinated substances in human food and other sources of human exposure. Rev. Environ. Contam. Toxicol. 208, 179-215.

Domingo, J.L., Jogsten, I.E., Eriksson, U., Martorell, I., Perelló, G., Nadal, M., van Bavel, B. 2012. Human dietary exposure to perfluoroalkyl substances in Catalonia, Spain. Temporal trend. Food Chem. 135, 1575-1582.

ECHA (European Chemicals Agency), 2013. Candidate List of Substances of Very High Concern for Authorisation. https://echa.europa.eu/home.

Ericson Jogsten, I., Nadal, M., van Bavel, B., Lindström, G., Domingo, J.L., 2012. Per- and polyfluorinated compounds (PFCs) in house dust and indoor air in Catalonia, Spain: implications for human exposure. Environ. Int. 39, 172-180.

Eriksson, U., Roos, A., Lind, Y., Hope, K., Ekblad, A., Kärrman, A., 2016. Comparison of PFASs contamination in the freshwater and terrestrial environments by analysis of eggs from osprey (Pandion haliaetus), tawny owl (Strix aluco), and common kestrel (Falco tinnunculus). Environ. Res. 149, 40-47.

Fei, C., McLaughlin, J.K., Tarone, R.E., Olsen, J., 2007. Perfluorinated chemicals and fetal growth: a study within the Danish National Birth Cohort. Environ. Health Perspect. 1677-1682.

Fromme, H., Tittlemier, S.A., Völkel, W., Wilhelm, M., Twardella, D., 2009. Perfluorinated compounds-exposure assessment for the general population in Western countries. Int. J. Hyg. Environ. Health 212, 239-270.

Gebbink, W.A., Glynn, A., Darnerud, P.O., Berger, U., 2015. Perfluoroalkyl acids and their precursors in Swedish food: the relative importance of direct and indirect dietary exposure. Environ. Pollut. 198, 108-115.

Geiger, S.D., Xiao, J., Shankar, A., 2013. Positive association between perfluoroalkyl chemicals and hyperuricemia in children. Am. J. Epidemiol. 177, 1255-1262.

Giesy, J.P., Kannan, K., 2001. Global distribution of perfluorooctane sulfonate in wildlife. Environ. Sci. Technol. 35, 1339-1342.

Guerranti, C., Perra, G., Corsolini, S., Focardi, S.E., 2013. Pilot study on levels of perfluorooctane sulfonic acid (PFOS) and perfluorooctanoic acid (PFOA) in selected foodstuffs and human milk from Italy. Food Chem. 140, 197-203.

Hansen, K.J., Clemen, L.A., Ellefson, M.E., Johnson, H.O., 2001. Compound-specific, quantitative characterization of organic fluorochemicals in biological matrices. Environ. Sci. Technol. 35, 766-770.

Haug, L.S., Salihovic, S., Jogsten, I.E., Thomsen, C., van Bavel, B., Lindström, G., Becher, G., 2010. Levels in food and beverages and daily intake of perfluorinated compounds in Norway. Chemosphere 80, 1137-1143.

Hoogenboom, R.L.A.P., Ten Dam, G., van Bruggen, M., Jeurissen, S.M.F., van Leeuwen, S.P.J., Theelen, R.M.C., Zeilmaker, M.J., 2016. Polychlorinated dibenzo-p-dioxins and dibenzofurans (PCDD/Fs) and biphenyls (PCBs) in home-produced eggs. Chemosphere 150, 311-319.

Iddamalgoda, A., Hayashi, S., Goto, E., Sugiyama, M., Oguri, K., 2001. Current Asian trends in egg production and consumption: a demand analysis of selected countries. World Poul. Sci. J. 57, 49-54.

Jiang, Q., Lust, R.M., Strynar, M.J., Dagnino, S., DeWitt, J.C., 2012. Perflurooctanoic acid induces developmental cardiotoxicity in chicken embryos and hatchlings. Toxicology 293, 97-106.

Johansson, J.H., Berger, U., Vestergren, R., Cousins, I.T., Bignert, A., Glynn, A., Darnerud, P.O., 2014. Temporal trends (1999-2010) of perfluoroalkyl acids in commonly consumed food items. Environ. Pollut. 188, 102-108.

Krippner, J., Brunn, H., Falk, S., Georgii, S., Schubert, S., Stahl, T., 2014. Effects of chain length and $\mathrm{pH}$ on the uptake and distribution of perfluoroalkyl substances in maize (Zea mays). Chemosphere 94, 85-90.

Lau, C., Anitole, K., Hodes, C., Lai, D., Pfahles-Hutchens, A., Seed, J., 2007. Perfluoroalkyl acids: a review of monitoring and toxicological findings. Toxicol. Sci. 99, 366-394.

Liu, Z., Lu, Y., Wang, T., Wang, P., Li, Q., Johnson, A.C., Sarvajayakesavalu, S., Sweetman, A.J., 2016. Risk assessment and source identification of perfluoroalkyl acids in surface and ground water: spatial distribution around a mega-fluorochemical industrial park, China. Environ. Int. 91, 69-77.

Lorenzo, M., Campo, J., Farré, M., Pérez, F., Picó, Y., Barceló, D., 2016. Perfluoroalkyl substances in the Ebro and Guadalquivir river basins (Spain). Sci. Total Environ. 540, 191-199.

Nelson, J.W., Hatch, E.E., Webster, T.F., 2010. Exposure to polyfluoroalkyl chemicals and cholesterol, body weight, and insulin resistance in the general US population. Environ. Health Perspect. 118, 197-202

Pérez, F., Nadal, M., Navarro-Ortega, A., Fàbrega, F., Domingo, J.L., Barceló, D., Farré, M., 2013. Accumulation of perfluoroalkyl substances in human tissues. Environ. Int. 59, 354-362.

Polder, A., Müller, M.B., Brynildsrud, O.B., de Boer, J., Hamers, T., Kamstra, J.H., Lie, E., Mdegela, R.H., Moberg, H., Nonga, H.E., Sandvik, M., Skaare, J.U., Lyche, J.L., 2016. Dioxins, PCBs, chlorinated pesticides and brominated flame retardants in free-range chicken eggs from peri-urban areas in Arusha, Tanzania: Levels and implications for human health. Sci. Total Environ. 551-552, 656-667.

Radzevičienè, L., Ostrauskas, R., 2012. Egg consumption and the risk of type 2 diabetes mellitus: a case-control study. Public Health Nutr. 15, 1437-1441.

Schecter, A., Colacino, J., Haffner, D., Patel, K., Opel, M., Päpke, O., Birnbaum, L., 2010 Perfluorinated compounds, polychlorinated biphenyls, and organochlorine pesticide contamination in composite food samples from Dallas, Texas, USA. Environ. Health Perspect. 118, 796-802.

SDSB (Shandong Statistical Bureau), 2015. Shandong Statistical Yearbook. http://www. stats-sd.gov.cn/tjnj/nj2015/indexch.htm.

Shan, G., Wang, Z., Zhou, L., Du, P., Luo, X., Wu, Q., Zhu, L., 2016. Impacts of daily intakes on the isomeric profiles of perfluoroalkyl substances (PFASs) in human serum. Environ. Int. 89-90, 62-70.

Spence, J.D., Jenkins, D.J.A., Davignon, J., 2010. Dietary cholesterol and egg yolks: not for patients at risk of vascular disease. Can. J. of Cardiol. e336-e339.

Steenland, K., Tinker, S., Shankar, A., Ducatman, A., 2010. Association of perfluorooctanoic acid (PFOA) and perfluorooctane sulfonate (PFOS) with uric acid among adults with elevated community exposure to PFOA. Environ. Health Perspect. 118, 229-233.

Stein, C.R., Savitz, D.A., Dougan, M., 2009. Serum levels of perfluorooctanoic acid and perfluorooctane sulfonate and pregnancy outcome. Am. J. Epidemiol. 170, 837-846.

Su, H., Lu, Y., Wang, P., Shi, Y., Li, Q., Zhou, Y., Johnson, A.C., 2016. Perfluoroalkyl acids (PFAAs) in indoor and outdoor dusts around a mega fluorochemical industrial park in China: implications for human exposure. Environ. Int. 94, 667-673.

Thayer, K., Houlihan, J., 2002. Perfluorinated Chemicals: Justification for Inclusion of this Chemical Class in the National Report on Human Exposure to Environmenta Chemicals. Environmental Working Group, Washington, DC.

UNEP (United Nations Environment Programme), 2009. Report of the Conference of the Parties of the Stockholm Convention on Persistent Organic Pollutants on the Work of its Fourth Meeting. http://chm.pops.int/TheConvention/ConferenceoftheParties/ ReportsandDecisions/tabid/208/Default.aspx.

Van Overmeire, I., Waegeneers, N., Sioen, I., Bilau, M., De Henauw, S., Goeyens, L. Pussemier, L., Eppe, G., 2009. PCDD/Fs and dioxin-like PCBs in home-produced eggs from Belgium: levels, contamination sources and health risks. Sci. Total Environ. 407, 4419-4429.

Waegeneers, N., De Steur, H., De Temmerman, L., Van Steenwinkel, S., Gellynck, X., Viaene J., 2009. Transfer of soil contaminants to home-produced eggs and preventive measures to reduce contamination. Sci. Total Environ. 407, 4438-4446.

Wang, P., Lu, Y., Wang, T., Meng, J., Li, Q., Zhu, Z., Sun, Y., Wang, R., Giesy, J.P., 2016. Shifts in production of perfluoroalkyl acids affect emissions and concentrations in the environment of the Xiaoqing River Basin, China. J. Hazard. Mater. 307, 55-63.

Wang, P., Lu, Y., Wang, T., Zhu, Z., Li, Q., Zhang, Y., Fu, Y., Xiao, Y., Giesy, J.P., 2015. Transport of short-chain perfluoroalkyl acids from concentrated fluoropolymer facilities to the Daling River estuary, China. Environ. Sci. Pollut. Res. 1-11.

Wang, T., Wang, P., Meng, J., Liu, S., Lu, Y., Khim, J.S., Giesy, J.P., 2014. A review of sources, multimedia distribution and health risks of perfluoroalkyl acids (PFAAs) in China. Chemosphere.

Wang, Y., Fu, J., Wang, T., Liang, Y., Pan, Y., Cai, Y., Jiang, G., 2010. Distribution of perfluorooctane sulfonate and other perfluorochemicals in the ambient environment around a manufacturing facility in China. Environ. Sci. Technol. 44, 8062-8067.

Wang, Y., Yeung, L.W.Y., Yamashita, N., Taniyasu, S., So, M.K., Murphy, M.B., Lam, P.K.S. 2008. Perfluorooctane sulfonate (PFOS) and related fluorochemicals in chicken egg in China. Chin. Sci. Bull. 53, 501-507.

Zafeiraki, E., Costopoulou, D., Vassiliadou, I., Leondiadis, L., Dassenakis, E., Hoogenboom, R.L., van Leeuwen, S.P., 2016. Perfluoroalkylated substances (PFASs) in home and commercially produced chicken eggs from the Netherlands and Greece. Chemosphere 144, 2106-2112.

Zhang T., Sun, H.W., Wu, Q Z Zhang XZ Z Yun, S.H., Kannan, K. 2010. Perfluorochemicals in meat, eggs and indoor dust in China: assessment of sources and pathways of human exposure to perfluorochemicals. Environ. Sci. Technol. 44, 3572-3579.

Zheng, X., Wu, J., Luo, X., Zeng, Y., She, Y., Mai, B., 2012. Halogenated flame retardants in home-produced eggs from an electronic waste recycling region in South China: levels, composition profiles, and human dietary exposure assessment. Environ. Int. $45,122-128$. 